\title{
Diagnostic yield and postoperative mortality associated with surgical lung biopsy for evaluation of interstitial lung diseases: A systematic review and meta-analysis
}

Qian Han, MD, PhD, Qun Luo, MD, PhD, Jia-Xing Xie, MD, PhD, Lu-Lu Wu, MD, Li-Yue Liao, MD, Xiao-Xian Zhang, MD, and Rong-Chang Chen, $\mathrm{MD}, \mathrm{PhD}$

Objectives: Surgical lung biopsy plays an important role in providing pathologic results, thus complementing the diagnostic rationale for suspected interstitial lung diseases. We performed a systematic review and metaanalysis regarding the diagnostic yield and postoperative mortality rate of surgical lung biopsy in patients with suspected interstitial lung diseases because of the wide variation in previously reported effectiveness and safety concerns.

\begin{abstract}
Methods: We systematically searched for published studies between 2000 and 2014 evaluating surgical lung biopsy in the diagnosis of interstitial lung diseases. Subgroup analysis was performed to identify the possible source of study heterogeneity.

Results: Twenty-three studies contributed 2148 patients for the analysis. The median diagnostic yield was $95 \%$ (range, $42 \%-100 \%$ ), with idiopathic pulmonary fibrosis as the most frequent diagnosis $(618,33.5 \%)$ ). Surgical lung biopsy was mainly guided by high-resolution computed tomography manifestations. Biopsy site, biopsy number, and the surgical lung biopsy method may not be associated with the diagnostic accuracy. The pooled postoperative mortality rate for included studies was 3.6\% (95\% confidence interval, 2.1-5.5), with significant heterogeneity observed. Subgroup analysis revealed that exclusion criteria based on immunocompromised status, mechanical ventilation, and severe respiratory dysfunction (diffusing capacity of lung for carbon monoxide $<35 \%$ or forced vital capacity $<55 \%$ predicted), but not surgical lung biopsy technique or underlying interstitial lung disease subtype, may be possible sources of heterogeneity.

Conclusions: We demonstrated a satisfactory diagnostic performance with a favorable safety profile of surgical lung biopsy in the diagnosis of suspected interstitial lung diseases. Surgical lung biopsy is especially recommended in patients with clinical information indicative but atypical of idiopathic pulmonary fibrosis, whereas the benefit of surgical lung biopsy should be carefully balanced against the risk for patients with immunocompromised status, mechanical ventilation dependence, or severe respiratory dysfunction. (J Thorac Cardiovasc Surg 2015;149:1394-401)
\end{abstract}

See related commentary pages $1402-3$.

Supplemental material is available online.

From the Division of Respiratory Medicine, Guangzhou Institute of Respiratory Disease, The First Affiliated Hospital of Guangzhou Medical University, Guangzhou, China.

This work was supported by National Natural Science Foundation of China Young Investigator Funding 2014-2016 (NO. 81300063).

Disclosures: Authors have nothing to disclose with regard to commercial support.

Drs Qian and Qun contributed equally to this article.

Received for publication Oct 10, 2014; revisions received Dec 12, 2014; accepted for publication Dec 25, 2014; available ahead of print Jan 31, 2015.

Address for reprints: Rong-Chang Chen, MD, PhD, Division of Respiratory Medicine, Guangzhou Institute of Respiratory Disease, The First Affiliated Hospital of Guangzhou Medical University, 151 Yanjiang Rd, Guangzhou, China (E-mail: chenrc@vip.163.com).

$0022-5223 / \$ 36.00$

Copyright (c) 2015 by The American Association for Thoracic Surgery

http://dx.doi.org/10.1016/j.jtcvs.2014.12.057
Interstitial lung diseases (ILDs) comprise a group of lung diseases with a great diversity regarding the cause, pathologic change, treatment, and prognosis. Therefore, the establishment of an accurate diagnosis is essential to determine the therapeutic intervention and prognosis for a given patient. Histologic results may be required to establish a specific diagnosis or complement diagnostic rationale in cases that remain undefined after thorough clinical information combined with thoracic imaging. Bronchoalveolar lavage or transbronchial lung biopsy via bronchoscopy may be useful in selected subtypes, such as sarcoidosis, hypersensitivity pneumonitis (HP), and eosinophilic pneumonia. However, transbronchoscopic sampling may not be representative and indicative because of the amount and size of biopsies.

The current guidelines emphasize the significant role of surgical lung biopsy (SLB) for the definite diagnosis of ILDs, ${ }^{1,2}$ whereas it may be associated with a relatively higher morbidity and mortality rate. Therefore, the final decision regarding whether or not to perform a SLB must 


$$
\begin{aligned}
& \text { Abbreviations and Acronyms } \\
& \begin{aligned}
& \text { CI }=\text { confidence interval } \\
& \text { DLCO }= \text { diffusing lung capacity for carbon } \\
& \text { monoxide } \\
& \text { FVC }=\text { forced vital capacity } \\
& \text { HP }=\text { hypersensitivity pneumonitis } \\
& \text { HRCT }=\text { high-resolution computed tomography } \\
& \text { ILD }=\text { interstitial lung disease } \\
& \text { IPF }=\text { idiopathic pulmonary fibrosis } \\
& \text { MV }=\text { mechanical ventilation } \\
& \text { NSIP }=\text { nonspecific interstitial pneumonia } \\
& \text { OLB }=\text { open lung biopsy } \\
& \text { SLB }=\text { surgical lung biopsy } \\
& \text { VATS }=\text { video-assisted thoracoscopic surgery }
\end{aligned}
\end{aligned}
$$

be based on the balance between benefits to establish a secure diagnosis and the potential risks. Numerous groups have published their experience with SLB in the diagnosis of ILDs. We conducted a systematic review to evaluate the effectiveness and safety of SLB in the diagnosis of ILDs, and meta-analysis were performed where applicable.

\section{MATERIALS AND METHODS}

We followed the Preferred Reporting Items for Systematic Reviews and Meta-Analyses Statement, and the study protocol was approved by the Ethics Committee of Guangzhou Medical University.

\section{Literature Search}

A systematic search of 2 databases (PubMed and Embase) for relevant citations (from January 1, 2000 to June 30, 2014) was performed in May 2014, with the following search terms used: "surgical lung biopsy" or "open lung biopsy" or "video-assisted thoracoscopic surgery" or "video-assisted thoracoscopy surgery" in combination with "interstitial lung disease" or "interstitial lung diseases" or "diffuse parenchymal lung disease." The search was restricted to human subjects. Bibliographies from selected articles and major reviews were screened for additional relevant publications that were not identified by the database search.

\section{Outcome Definitions}

Two outcomes for this systematic review were diagnostic yield and postoperative mortality. Diagnostic yield indicated the specific diagnosis obtained with SLB samples thus affecting overall patient management. Postoperative mortality was defined as the number of patients who died within 90 days after surgery.

\section{Selection of Studies}

Two authors (HQ and LQ) independently reviewed all articles identified by the search strategy for inclusion in this review, sequentially evaluating the title, abstract, and full publication. Discordance was resolved by consensus. Inclusion criteria were as follows: (1) SLB, including both video-assisted thoracoscopic surgery (VATS) and open lung biopsy (OLB) for the diagnosis of suspected ILDs; (2) reported at least 1 of primary outcomes; (3) enrolled at least 30 patients; and (4) published in English. We excluded abstracts, editorials, reviews, and case reports. Studies describing the diagnostic yield of SLB in a specific subset of patients were also excluded. In the event of multiple publications with overlapping study periods, we included only 1 study with the largest number to prevent double counting of the patient cohorts. Authors of studies not reporting sufficient data were contacted to request additional information.

\section{Data Extraction and Quality Assessment}

Data were recorded on a standard data extraction form that included the following items: description of study population (number, age, geographic location, and surgery methods); study design (prospective or retrospective); patient enrollment (key inclusion and exclusion criteria); biopsy site; and number. The quality and validity of each article were assessed using the QualSyst tool for quantitative studies. ${ }^{3}$ This tool was based on the study design, method of population sampling, strategies of data collection and analysis, and how the conclusions were ascertained. It consists of 14 questions with scores from 0 to 2, with the maximum total score being 28 .

\section{Data Synthesis and Statistical Analysis}

We conducted a meta-analysis for mortality rate using the variancestabilization double arc-sine transformation method, ${ }^{4}$ because the inverse variance weight in meta-analyses is suboptimum when dealing with binary data with low mortality rates. We applied DerSimonian-Laird weights for the random effects model where heterogeneity between studies was found. The pooled rate can be calculated as the back-transform of the weighted mean of the transformed rates. The impact of statistical heterogeneity on the pooled estimates of individual outcomes was assessed using the $I^{2}$ test, which measures the extent of inconsistency among the results of the studies. An $I^{2}$ value greater than $50 \%$ indicates significant heterogeneity. Subgroup analysis was performed if heterogeneity was demonstrated, according to common methodological/clinical features of the studies. Statsdirect and STATA 12.0 (StatsDirect Ltd, Altrincham, UK) were used to perform all the tests.

\section{RESULTS}

\section{Literature Search and Study Selection}

The selection of included studies is summarized in Figure 1. Screening of titles and abstracts identified 30 articles for full text review. Of these, 7 articles were excluded: Four articles focused on a special subset of patients, such as those with idiopathic pulmonary fibrosis (IPF) or idiopathic interstitial pneumonia, and those dependent on mechanical ventilation (MV); 2 articles evaluated a certain aspect of SLB in the diagnosis of ILDs; and 1 article recruited only 20 patients. Finally, 23 articles met the eligibility criteria of our systematic review.

\section{Study Description and Quality Assessment}

Study characteristics are recorded in Table 1. A total of 2148 patients with suspected ILDs undergoing SLB were included (range, $30-311$ patients per study). There were 5 prospective studies and 18 retrospective studies. Three studies were multicenter studies, including 1 retrospective study and 2 prospective studies; others were studies from a single institution.

The quality of studies was generally acceptable, with a median (interquartile) QualSyst score of 21 (range, 17-24) (Table 2). None of the studies were designed as a "double-blind" procedure and could be assessable in "blinding of investigators/subjects" domains. Moreover, 


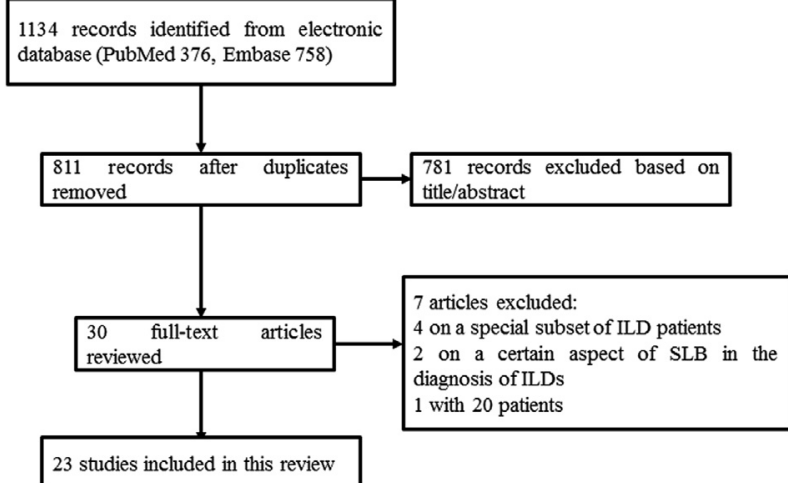

FIGURE 1. Selection of included studies from systematic review. ILD, Interstitial lung disease; $S L B$, surgical lung biopsy.

only 2 prospective randomized, controlled studies were assessable in "random allocation" domain. 5,6

\section{Subject Characteristics}

The mean age of patients ranged from 36.1 to 62.0 years, and $1124(52.3 \%)$ were male. All patients had suspected
ILDs yet remained undefined or unclassified with thorough clinical and radiologic information. There were 1632 patients undergoing VATS $(76.0 \%)$ and 268 patients undergoing OLB $(12.5 \%)$ in 21 studies reporting SLB techniques.

\section{Diagnostic Yield}

The diagnostic yield for each included study is summarized in Table 2. A formal meta-analysis was not performed because of the heterogeneity of included studies. The median diagnostic yield was $95 \%$ (range, $42 \%-100 \%$ ), with only 1 study achieving less than $70 \%,{ }^{7} 8$ studies achieving $70 \%$ to $90 \%,{ }^{8-15} 8$ studies achieving $90 \%$ to $100 \%,{ }^{5,16-20}$ and 6 studies achieving $100 \%{ }^{6,21-25}$ Moreover, 8 studies evaluated the frequency in which the biopsy changed the treatment algorithm, ranging from $42 \%$ to $90 \%$. ${ }^{7,8,10,15,18,20,22,24}$ The change was driven by specific diagnosis in 6 studies ${ }^{8,15,18,20,22,24}$ and was not necessarily related to specific diagnosis in 2 studies. ${ }^{7,10}$

A total of 17 studies reported biopsy sites; 11 studies were guided by computed tomography without special

TABLE 1. Main characteristics of selected studies

\begin{tabular}{|c|c|c|c|c|c|c|c|}
\hline First author & Year & Country & $\begin{array}{c}\text { Patients n } \\
\text { (male/female) }\end{array}$ & $\begin{array}{l}\text { Mean } \\
\text { age, } y\end{array}$ & Study design & Patient enrollment & Exclusion criteria \\
\hline Ayed $^{5}$ & 2000 & Kuwait & $61(36 / 25)$ & 39.8 & $\mathrm{RCT}$ & NA & MV dependence \\
\hline Miller $^{6}$ & 2000 & US & $42(23 / 19)$ & 52.4 & $\mathrm{RCT}$ ( 4 centers) & Consecutive (ambulatory) & NA \\
\hline Blewett ${ }^{21}$ & 2001 & Canada & $32(\mathrm{ND})$ & 58 & Retrospective & Consecutive (ambulatory) & Oxygen dependence, acute illness \\
\hline Qureshi $^{7}$ & 2002 & UK & $100(59 / 41)$ & 51.5 & Retrospective & NA & MV dependence \\
\hline Ayed $^{26}$ & 2003 & Kuwait & $79(50 / 29)$ & 38.9 & Prospective & NA & MV dependence \\
\hline Yamaguchi $^{24}$ & 2004 & Japan & $30(18 / 12)$ & 56.7 & Retrospective & Consecutive & $\begin{array}{c}\text { Immunocompromised or MV } \\
\text { dependence }\end{array}$ \\
\hline Lettieri $^{22}$ & 2005 & US & $83(48 / 35)$ & 57.3 & Retrospective & NA & Age $<18$ y \\
\hline $\mathrm{Oooi}^{14}$ & 2005 & UK & $70(57 / 13)$ & 56 & Retrospective & Consecutive & Histologic diagnoses not ILD \\
\hline Kreider $^{13}$ & 2007 & US & $68(30 / 38)$ & 58 & Retrospective & Consecutive (ambulatory) & NA \\
\hline Bando $^{16}$ & 2008 & Japan & $94(43 / 51)$ & 59 & Retrospective & NA & AE before surgery \\
\hline Ishie $^{27}$ & 2008 & Brazil & $48(23 / 25)$ & 58.8 & Retrospective & NA & MV and oxygen dependence \\
\hline Coutinho $^{25}$ & 2008 & Portugal & $120(60 / 60)$ & 55.8 & Retrospective & Consecutive & NA \\
\hline Sigurdsson ${ }^{15}$ & 2009 & Iceland & $73(42 / 31)$ & 57.3 & $\begin{array}{l}\text { Retrospective } \\
\quad \text { (nationwide) }\end{array}$ & Consecutive & NA \\
\hline Guerra $^{17}$ & 2009 & Portugal & $53(31 / 22)$ & 47.2 & Retrospective & NA & NA \\
\hline Fibla $^{10}$ & 2012 & US & $311(164 / 147)$ & 60.9 & Retrospective & Consecutive & NA \\
\hline Fibla $^{11}$ & 2012 & Spain & $224(106 / 118)$ & 57.1 & $\begin{array}{l}\text { Prospective } \\
\quad(13 \text { centers })\end{array}$ & Consecutive (some ambulatory) & $\begin{array}{l}\text { MV dependence or } \\
\mathrm{PaO}_{2}<60 \mathrm{~mm} \mathrm{Hg}\end{array}$ \\
\hline Blackhall $^{8}$ & 2012 & UK & $103(51 / 52)$ & 58 & Retrospective & Consecutive & NA \\
\hline Blanco $^{9}$ & 2012 & Spain & $156(82 / 89)$ & 57.3 & Retrospective & NA & NA \\
\hline Luo $^{23}$ & 2013 & China & $32(20 / 12)$ & 52.2 & Retrospective & NA & MV dependence or DLCO $<50 \%$ \\
\hline Pompeo $^{19}$ & 2013 & Italy & $30(15 / 15)$ & 62 & Prospective & NA & $\begin{array}{c}\text { Age }>75 \mathrm{y}, \mathrm{MV} \text { dependence, } \\
\mathrm{DLCO}<30 \% \text {, AE in past } 6 \mathrm{mo}, \\
\quad \mathrm{PaO}_{2}<50 \mathrm{~mm} \mathrm{Hg}\end{array}$ \\
\hline Kayatta $^{12}$ & 2013 & US & $194(100 / 94)$ & 58 & Retrospective & Consecutive & NA \\
\hline Morris $^{18}$ & 2014 & UK & $66(31 / 35)$ & 58.9 & Retrospective & Consecutive & NA \\
\hline Sonobe $^{20}$ & 2014 & Japan & $64(35 / 29)$ & 57 & Prospective & NA & $\begin{array}{c}\text { Age }>70 \text { y, FVC }<60 \%, \\
\text { DLCO }<40 \%\end{array}$ \\
\hline
\end{tabular}

$R C T$, Randomized controlled trial; $N A$, not available; $N D$, not determined; $M V$, mechanical ventilation; $I L D$, interstitial lung disease; $A E$, acute exacerbation; $P a O_{2}$, arterial oxygen tension; $D L C O$, diffusing lung capacity for carbon monoxide; $F V C$, forced vital capacity. 
TABLE 2. Outcomes and quality of included studies

\begin{tabular}{|c|c|c|c|c|c|c|c|c|c|c|c|}
\hline First author & Year & $\begin{array}{c}\text { Patient } \\
\text { no. }\end{array}$ & $\begin{array}{c}\text { Diagnostic } \\
\text { yield }(\%)\end{array}$ & $\begin{array}{l}\text { Treatment } \\
\text { change }(\%)\end{array}$ & $\begin{array}{c}\text { Biopsy } \\
\text { location }\end{array}$ & Biopsy no. (n) & $\begin{array}{c}\text { Surgery } \\
\text { method (n) }\end{array}$ & $\begin{array}{c}\text { 30-d } \\
\text { mortality }(\%)\end{array}$ & $\begin{array}{c}\text { 90-d } \\
\text { mortality }(\%)\end{array}$ & $\begin{array}{l}\text { Postoperative } \\
\text { mortality }(\%)\end{array}$ & $\begin{array}{l}\text { Total } \\
\text { score }\end{array}$ \\
\hline Ayed $^{5}$ & 2000 & 61 & 95.1 & NA & $\mathrm{CT}$ & 2 & $\begin{array}{l}\text { VATS (61) } \\
\text { OLB (29) }\end{array}$ & 1.6 & 3.3 & 3.3 & 24 \\
\hline Miller $^{6}$ & 2000 & 42 & 100.0 & NA & NA & 1.6 (mean) & $\begin{array}{l}\text { VATS (42) } \\
\text { OLB (22) }\end{array}$ & 0.0 & 2.4 & 2.4 & 23 \\
\hline Blewett $^{21}$ & 2001 & 32 & 100.0 & NA & Lingula & 2 & OLB & NA & NA & NA & 20 \\
\hline Qureshi $^{7}$ & 2002 & 100 & 42.0 & 59.5 & $\mathrm{CT}$ & $1(69) / \geq 2(31)$ & $\begin{array}{l}\text { VATS (70) } \\
\text { OLB (30) }\end{array}$ & NA & $\mathrm{NA}$ & NA & 21 \\
\hline Ayed $^{26}$ & 2003 & 79 & 96.2 & NA & $\begin{array}{r}34 \text { (middle), } \\
45 \text { (other) }\end{array}$ & $1(34) / 2(45)$ & VATS & NA & NA & NA & 21 \\
\hline Yamaguchi $^{24}$ & 2004 & 30 & 100.0 & 57.0 & CT & $\begin{array}{l}1(17) / 2 \\
(11) / 3(2)\end{array}$ & VATS & 0.0 & 0.0 & 0.0 & 20 \\
\hline Lettieri $^{22}$ & 2005 & 83 & 100.0 & 84.0 & NA & NA & $\begin{array}{l}\text { VATS (60) } \\
\text { OLB (23) }\end{array}$ & 4.8 & 6.0 & 6.0 & 22 \\
\hline $\mathrm{Ooi}^{14}$ & 2005 & 70 & 81.4 & NA & $\mathrm{NA}$ & $\mathrm{NA}$ & $\begin{array}{l}\text { VATS (55) } \\
\text { OLB (15) }\end{array}$ & NA & NA & $\mathrm{NA}$ & 17 \\
\hline Kreider $^{13}$ & 2007 & 68 & 76.5 & NA & NA & NA & VATS & 2.9 & 4.4 & 4.4 & 22 \\
\hline Bando $^{16}$ & 2008 & 94 & 96.8 & NA & $\begin{array}{l}\text { Upper and } \\
\text { lower lobes }\end{array}$ & $\geq 2$ & VATS & 0.0 & 2.1 & 2.1 & 22 \\
\hline Ishie $^{27}$ & 2008 & 48 & 95.8 & NA & NA & $1(42) / 2(6)$ & VATS & NA & NA & NA & 20 \\
\hline Coutinho $^{25}$ & 2008 & 120 & 100.0 & NA & $\mathrm{CT}$ & 2 & $\mathrm{NA}$ & NA & NA & NA & 19 \\
\hline Sigurdsson $^{15}$ & 2009 & 73 & 83.6 & 53.0 & CT & $1(51) / 2(17)$ & $\begin{array}{l}\text { VATS (28) } \\
\text { OLB (45) }\end{array}$ & 2.7 & 4.1 & 4.1 & 21 \\
\hline Guerra $^{17}$ & 2009 & 53 & 94.3 & NA & CT & $2-3$ & $\begin{array}{l}\text { VATS (37) } \\
\text { OLB (16) }\end{array}$ & 1.9 & NA & 1.9 & 18 \\
\hline Fibla $^{10}$ & 2012 & 224 & 87.1 & NA & $\mathrm{CT}$ & $1(45) / 2(179)$ & $\begin{array}{l}\text { VATS (279) } \\
\text { OLB (32) }\end{array}$ & NA & NA & NA & 20 \\
\hline Fibla $^{11}$ & 2012 & 311 & 80.7 & 90.0 & NA & $\begin{array}{c}1(50) / 2(198) / 3 \\
(59) / 4(4)\end{array}$ & VATS & 9.0 & 10.6 & 10.6 & 22 \\
\hline Blackhall $^{8}$ & 2012 & 103 & 69.9 & 45.6 & $\begin{array}{l}\text { Right is } \\
\text { preferred }\end{array}$ & 2 is preferred & NA & 4.9 & NA & 4.9 & 20 \\
\hline Blanco $^{9}$ & 2012 & 171 & 78.4 & NA & NA & $2-3$ & $\begin{array}{l}\text { VATS (141) } \\
\text { OLB (15) }\end{array}$ & NA & 5.8 & 5.8 & 18 \\
\hline $\mathrm{Luo}^{23}$ & 2013 & 32 & 100.0 & NA & CT & 1.3 (mean) & VATS & 0.0 & 3.1 & 3.1 & 21 \\
\hline Pompeo $^{19}$ & 2013 & 30 & 96.7 & NA & CT & NA & VATS & 0.0 & 0.0 & 0.0 & 22 \\
\hline Kayatta $^{12}$ & 2013 & 194 & 88.7 & NA & $\mathrm{NA}$ & $2-3$ & VATS & NA & 6.7 & 6.7 & 20 \\
\hline Morris $^{18}$ & 2014 & 66 & 90.9 & 47.2 & $\mathrm{CT}$ & $1(38) / \geq 2(28)$ & VATS & 1.5 & 4.5 & 4.5 & 19 \\
\hline Sonobe $^{20}$ & 2014 & 64 & 96.9 & 51.6 & CT & $\begin{array}{l}1(8) / 2 \\
(53) / 3(3)\end{array}$ & $\begin{array}{l}\text { VATS (55) } \\
\text { OLB (9) }\end{array}$ & 0.0 & 0.0 & 0.0 & 21 \\
\hline
\end{tabular}

Biopsy No. is expressed as biopsy number (patient number) where applicable. $N A$, Not available; $C T$, computed tomography; VATS, video-assisted thoracoscopic surgery; $O L B$, open lung biopsy.

preference. There were 2 studies predisposed to right lobes, ${ }^{8,15}$ with a diagnostic yield of $84 \%$ and $94 \%$, respectively. One study avoided the lingual or middle lobe ${ }^{16}$ and 1 study focused on the lingular lobe,${ }^{21}$ reporting a diagnostic yield of $97 \%$ and $100 \%$, respectively. Two studies demonstrated that biopsy samples from the lingual or middle lobe have the same diagnostic yield as those from others. ${ }^{26,27}$

A total of 19 studies reported diagnostic performance based on biopsy number. A total of 12 studies obtained 1 to 3 samples, among which 8 studies suggested that 1 sample containing both lesion and normal tissue was sufficient to represent pathologic changes. $7,11,12,15,23,24,26,27$
Only 1 study stated that multiple biopsies may increase the diagnostic yield. ${ }^{8}$

A total of 21 studies specified SLB methods performed; 10 studies used both VATS and OLB, ${ }^{5-7,9,10,14,15,17,20,22}$ 10 studies used VATS, ${ }^{11-13,16,18,19,23,24,26,27}$ and 2 studies used OLB. ${ }^{21}$ Significant heterogeneity was still observed in subgroup analysis based on different surgical methods (data not shown). Sixteen studies evaluated the diagnostic yield of VATS in 1129 patients, varying from $44 \%$ to $100 \%$, and 7 studies evaluated the diagnostic yield of OLB in 167 patients, varying from $37 \%$ to $100 \%$. Six studies using both VATS and OLB compared the diagnostic yield of these 2 techniques, and no difference was noted. 


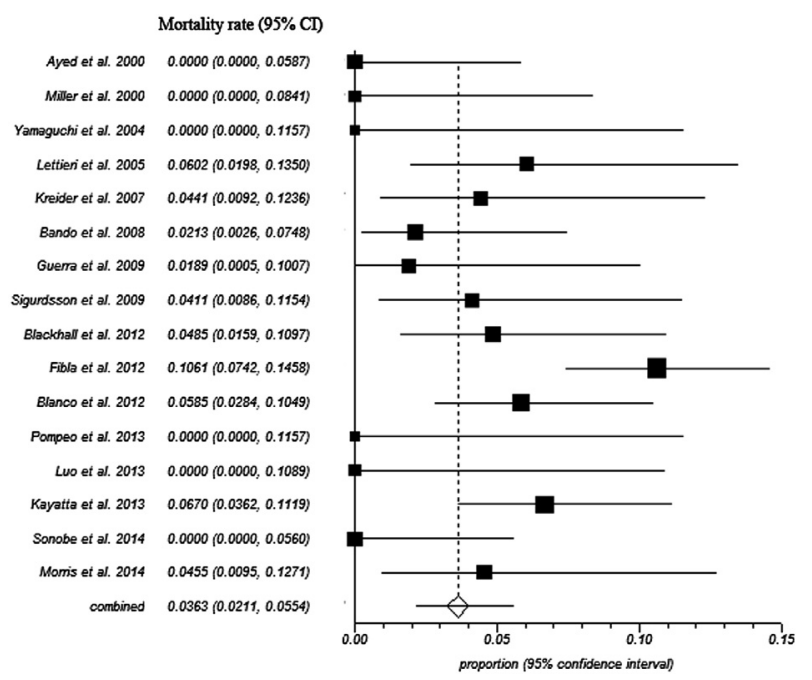

FIGURE 2. Forest plots of mortality rate. Squares represent point estimates of mortality rate from each study reporting results eligible for analysis. Solid lines represent 95\% CI. Inconsistency $\left(I^{2}\right), 65.4 \%$; chi-square, $43.35 ; P<.0001$. $C I$, Confidence interval.

The distribution of 1847 specific diagnoses made by SLB is summarized in Figure E1. IPF accounted for most cases $(618,33.5 \%)$, followed by nonspecific interstitial pneumonia (NSIP) $(219,11.9 \%)$, HP $(178,9.6 \%)$, cryptogenic organizing pneumonia $(139,7.5 \%)$, sarcoidosis $(126,6.8 \%)$, and connective tissue disease-related ILD (73, 4.0\%).

\section{Mortality Rates}

Only 16 studies presented sufficient data to allow inclusion in meta-analysis. $5,6,8-10,12,13,15-20,22-24$ The pooled 30 - and 90 -day mortality rates were $2.2 \%(95 \%$ confidence interval $[\mathrm{CI}], 1.0-4.0)$ and $3.4 \%(95 \% \mathrm{CI}$, 1.8-5.5), respectively (Table 2). The composite postoperative mortality was 3.6\% (95\% CI, 2.1-5.5) (Figure 2). Significant heterogeneity was observed among individual studies $\left(I^{2}, 65.4 \%\right.$; chi-square, $\left.43.35 ; P<.0001\right)$; therefore, subgroup analyses were applied to explore the possible source of heterogeneity.

Studies were evaluated on the basis of variable exclusion criteria, including age, immunocompromised status, MV dependence, and spirometry data (Table 3). Significant heterogeneity was witnessed between studies with patients aged more than 70 years and between studies excluding patients aged more than 70 years (data not shown). Subgroup analysis on 9 studies according to the immunocompromised status demonstrated no heterogeneity among studies excluding immunocompromised patients (mortality rate, $0.6 \% ; 95 \% \mathrm{CI}, 0.01-2.3 ; I^{2}, 0 \%$; chi-square, 0.09 ; $P=.993)$. Significant heterogeneity was noted among studies including immunocompromised patients (mortality rate, $6.1 \% ; 95 \% \mathrm{CI}, 3.1-10.1 ; I^{2}, 58.6 \%$; chi-square, 9.66; $P=.047)$.

Subgroup analysis strongly suggested that the exclusion of MV dependence is a source of heterogeneity in mortality of SLB among studies. Pooled statistics demonstrated an increased mortality rate for studies including MVdependent patients $(7.8 \%$; 95\% CI, 5.3-10.7) compared with those excluding MV-dependent patients $(2.4 \%$; $95 \%$ CI, 1.5-4.2) $(P<.001)$. Subgroup analysis was performed on 11 studies including MV-independent patients, and the heterogeneity was found to be further decreased among studies excluding patients with diffusing lung capacity for carbon monoxide (DLCO) less than $35 \%$ or forced vital capacity (FVC) less than $55 \%$ predicted $\left(I^{2}, 0 \%\right.$; chi-square, $1.35 ; P=.85$ ) but not among those including this subset of patients. Moreover, the pooled statistics demonstrated a mortality rate of $1.0 \%(95 \% \mathrm{CI}, 0.1-2.7)$ and $3.7 \%$ (95\% CI, 1.7-6.3) for 2 subgroups, respectively. This difference was significant $(P=.026)$.

Subgroup analysis based on the surgery methods revealed that the heterogeneity was decreased in studies performing VATS (mortality rate, $2.9 \%$; 95\% CI, 1.7-4.5; $I^{2}, 47.7 \%$; chi-square, $28.7 ; P=.018$ ), whereas significant heterogeneity was noted among studies using OLB (mortality rate,

TABLE 3. Results of subgroup analysis stratified by different exclusion criteria

\begin{tabular}{|c|c|c|c|c|c|}
\hline & Study n & Patient no. & Mortality \% (95\% CI) & $I^{2} \%$ & Chi-square test \\
\hline \multicolumn{6}{|c|}{ Exclusion of immunocompromised patients } \\
\hline Yes & $4^{6,20,23,24}$ & 168 & $0.6(0.01-2.3)$ & 0 & $0.09(P=.993)$ \\
\hline No & $5^{10,13,18,19,22}$ & 558 & $6.1(3.1-10.1)$ & 58.6 & $9.66(P=.047)$ \\
\hline \multicolumn{6}{|c|}{ Exclusion of MV dependence } \\
\hline Yes & $11^{5,8,9,13,16,17,19,20,23,24}$ & 706 & $2.4(1.5-4.2)$ & 40.9 & $16.93(P=.076)$ \\
\hline No & $4^{10,12,15,22}$ & 661 & $7.8(5.3-10.7)$ & 35.8 & $4.67(P=.198)$ \\
\hline \multicolumn{6}{|c|}{ Exclusion of patients with severe respiratory dysfunction* } \\
\hline Yes & $5^{5,16,17,19,23}$ & 216 & $1.0(0.1-2.7)$ & 0 & $1.35(P=.853)$ \\
\hline No & $6^{8,9,13,16,20,24}$ & 490 & $3.7(1.7-6.3)$ & 42.8 & $8.75(P=.12)$ \\
\hline \multicolumn{6}{|c|}{ SLB method } \\
\hline VATS & $16^{5-7,9,10,12,14,16-20,23,24,26}$ & 1295 & $2.9(1.7-4.5)$ & 47.7 & $28.7(P=.018)$ \\
\hline OLB & $8^{5-7,9,10,14,17,20}$ & 170 & $8.0(1.6-18.5)$ & 77.7 & $31.4(P<.0001)$ \\
\hline
\end{tabular}

$C I$, Confidence interval; $M V$, mechanical ventilation; $S L B$, surgical lung biopsy; VATS, video-assisted thoracoscopic surgery; $O L B$, open lung biopsy. *The population restricted to MV-independent patients. † $\nmid$ Severe respiratory dysfunction defined as DLCO $<35 \%$ or FVC $<55 \%$. 
$8.0 \% ; 95 \%$ CI, 1.6-18.5; $I^{2}, 77.7 \%$; chi-square, 31.4 ; $P<.0001)$. The surgery method also may contribute to heterogeneity, although the evidence supporting this contention is less clear.

Only 3 studies evaluated the mortality rate on the basis of underlying ILD subtypes. Bando and colleagues ${ }^{16}$ and Kreider and colleagues ${ }^{13}$ found all deaths were observed in IPF cases. However, Lettieri and colleagues ${ }^{22}$ demonstrated that the mortality rate was not related to the underlying ILD, although more deaths were observed in those with IPF compared with those without IPF.

\section{DISCUSSION}

Narrative reviews on SLB in the diagnosis of suspected ILDs have been published ${ }^{28,29}$; however, rigorous systematic evaluation was seldom performed because of the great variability of inclusion criteria, surgery expertise, and methodological quality of different studies. The results, based on our systematic review and meta-analysis, demonstrated a satisfactory diagnostic performance with the favorable safety profile of SLB for evaluation of suspected ILDs. The postoperative mortality may be related to MV dependence, severe respiratory dysfunction, and immunocompromised status, but not surgical method and underlying ILD subtype.

The diagnostic yield of SLB ranges from $42 \%$ to $100 \%$, with only 1 study achieving less than $70 \%$, in which the diagnoses were merely established on pathologic results. ${ }^{7}$ This result may indicate the importance and necessity of multidisciplinary consultation, including pulmonary physicians and radiologists with histopathologic conclusions. However, although change in therapy is usually based on specific diagnosis, ${ }^{30}$ the treatment algorithm was still altered in $55.2 \%$ of patients without specific diagnoses, comparable to $59.5 \%$ in patients with specific diagnoses. ${ }^{7}$ Fibla and colleagues ${ }^{10}$ also reported that $90 \%$ of treatment was changed with $81 \%$ of specific diagnoses achieved. These results suggested that an alteration in treatment may not be directed by a definitive histologic diagnosis and that nonspecific histologic results also could be useful in clinical practice.

Several studies have assessed factors that may influence the diagnostic effectiveness of SLB. Although the issue of appropriate biopsy site has entertained substantial controversy on whether or not to avoid the lingula or middle lobe, ${ }^{5,16,21}$ most studies suggested the guidance of highresolution computed tomography (HRCT) may be highly effective to identify active disease and appropriate biopsy location. In regard to the number of biopsies, multiple studies supported that only 1 biopsy may be representative as long as it contains both abnormal- and normal-appearing areas, because biopsies from less-involved areas of the lung may present an active and diagnosable process rather than end-stage nonspecific fibrosis. ${ }^{7,11,12,15,23,24,26,27}$ However, it should be noted that the evaluation of effective biopsy samples in future studies would be more accurate and meaningful if the biopsy number is combined with the sample size.

Significant heterogeneity was still noted in the subgroup analysis of diagnostic performance based on different surgical methods (ie, VATS and OLB). These results also supported previous observations that the yield of SLB may not be influenced by SLB techniques. ${ }^{5-8}$ The decision on which technique to use is usually driven by procedure familiarity of surgeons and patient conditions, such as the presence of extensive pleural adhesion and a noncompliant lung.

The most frequent diagnoses by SLB in a patient cohort with suspected ILD was IPF, with most patients being screened by HRCT examinations. In 2 studies comparing the diagnostic yield between HRCT and SLB, IPF was finally diagnosed by SLB in $75 \%$ to $91 \%$ of suspected cases, whereas $19.2 \%$ to $73.9 \%$ of IPF cases were not initially suspected by HRCT. ${ }^{14,15}$ These findings suggested that HRCT, although highly specific, is less sensitive in the diagnosis of IPF, therefore necessitating the utility of SLB in the diagnosis of these HRCT-omitted cases. In addition, there were 2 studies reporting $\operatorname{NSIP}^{17,23}$ and 2 studies reporting $\mathrm{HP}^{18,20}$ as the most common diagnoses. Further research is required to validate whether the diagnostic distinct is derived from the epidemiologic difference or interobserver disagreement among pathologists.

The safety issue is another important consideration when referring patients to SLB. Meta-analysis of 16 studies demonstrated a point postoperative mortality rate of $3.6 \%$ (95\% CI, 2.1-5.5) with significant heterogeneity noted $\left(I^{2}, 65.4 \%\right.$; chi-square, 43.35; $\left.P<.0001\right)$. Subgroup analysis suggested that the exclusion criteria based on MV dependence was a possible source of heterogeneity. The mortality rate was found to be significantly decreased in studies excluding mechanically ventilated patients. Two studies identified ventilator dependence as an independent risk factor for SLB mortality. ${ }^{12,22}$ However, the apparent increased mortality rate in mechanically ventilated patients was more likely to be related to the critical illness rather than the SLB procedure, because the comparison between survivors and nonsurvivors did not show a significant difference regarding the incidence of OLB complications. ${ }^{31}$ Therefore, it is overcautious and inappropriate to indiscreetly refuse SLB in this patient subset given that SLB may greatly benefit patients by validating diagnoses and directing therapeutic modifications.

In studies with MV-independent patients, the pooled mortality rate for studies excluding patients with DLCO less than $35 \%$ or FVC less than $55 \%$ was significantly reduced compared with those including this subset of patients, indicating that severe respiratory dysfunction, 
either compromise of gas exchange or ventilatory restriction, may be associated with a high risk for SLB. Moreover, the pooled mortality rate for studies excluding immunocompromised patients was significantly reduced compared with those lacking this exclusion criterion, suggesting that the immunocompromised status of patients may be another risk factor for postoperative mortality. Nevertheless, it is important to keep certain caveats in mind, because subgroups stratified by exclusion criteria did not actually divide study subjects into those with potential risk factors (eg, immunocompromised status, MV dependence, or severe respiratory dysfunction) and those without. Although subgroups with special exclusion criteria were free of high-risk patients, the subgroup lacking exclusion criteria would still contain many low-risk patients, and this may explain the relatively great heterogeneity within these groups. However, given the limited data at present, the subgroup analyses according to having or lacking these potential risk factors could not be performed, and further studies are required to validate the impact of these features on the mortality rate in SLB.

Subgroup analysis based on the surgery approach revealed that the surgery method also may contribute to heterogeneity, yet significant heterogeneity was still noted in studies performing OLB. Only 2 studies demonstrated a higher mortality rate in patients undergoing OLB compared with VATS. ${ }^{9,10}$ However, the retrospective nature of these studies may exaggerate the difference because the impact of specific surgeons' practices is often ignored. Two randomized studies have shown the opposite results with comparable morbidity and mortality rates between OLB and VATS procedures.

The relationship between the mortality rate and the underlying ILD subtype was controversial, especially in studies that specifically analyzed the mortality rate in patients with IPF: Tiitto and colleagues $^{32}$ reported a comparable 30-day mortality rate in patients with IPF undergoing SLB with other subtypes, whereas a considerably higher mortality was observed in patients with a usual interstitial pneumonia pattern histologically or in computed tomography scans in 2 studies, and preoperative low DLCO $\%$ and $\mathrm{FVC} \%$ were predictive parameters of postoperative death. ${ }^{33,34}$ These results suggested that a high mortality rate in patients with IPF may be accounted for by more severe respiratory dysfunction in this subset of patients. Prospective studies including patients with different ILD patterns (eg, usual interstitial pneumonia vs NSIP) with comparable respiratory function are required to determine the relative predict importance of ILD pattern in the postoperative mortality of SLB.

\section{Study Limitations}

Despite rigorous application of the QualSyst tool for included studies, most studies showed heterogeneity in the assessment of diagnostic yield. One possible reason was that the sensitivity of SLB partially depended on surgeon experience, which may be variable among different studies. In addition, some factors affecting the performance of SLB were not reported in the majority of studies. These include the size of biopsies and radiologic features. Finally, few included studies attempted to analyze potential risk factors of mortality using a rigorous multivariate regression method, perhaps because of the limited study population size with few fatalities. Despite these limitations, our analysis may set a foundation for future studies in this field and raise potential aspects for further investigation.

\section{CONCLUSIONS}

Our study demonstrated that the diagnostic performance of SLB for the investigation of suspected ILDs was good with a favorable safety profile. Postoperative mortality may be related to MV dependence, severe respiratory dysfunction, and immunocompromised status of patients. Multicenter prospective studies are warranted to evaluate the generalizability of results to more clearly defined patient populations, thereby allowing improved understanding of the influence on the diagnostic effectiveness and potential risks of SLB.

\section{References}

1. Raghu G, Collard HR, Egan JJ, Martinez FJ, Behr J, Brown KK, et al. An official ATS/ERS/JRS/ALAT statement: idiopathic pulmonary fibrosis: evidence-based guidelines for diagnosis and management. Am J Respir Crit Care Med. 2011; 183:788-824.

2. Travis WD, Costabel U, Hansell DM, King TE, Lynch DA, Nicholson AG, et al. An official American Thoracic Society/European Respiratory Society Statement: update of the international multidisciplinary classification of the idiopathic interstitial pneumonias. Am J Respir Crit Care Med. 2013;188:733-48.

3. Kmet L, Lee R, Cook L. Standard Quality Assessment Criteria for Evaluating primary Research Papers from a Variety of Fields. Edmonton: Alberta Heritage Foundation for Medical Research (AHFMR). HTA Initiative; 2004.

4. Freeman M, Tukey J. Transformations related to the angular and the square root. Ann Math Stat. 1950;21:607-11.

5. Ayed AK, Raghunathan R. Thoracoscopy versus open lung biopsy in the diagnosis of interstitial lung disease: a randomised controlled trial. J R Coll Surg Edinb. 2000;45:159-63.

6. Miller JD, Urschel JD, Cox G, Olak J, Young JE, Kay JM, et al. A randomized, controlled trial comparing thoracoscopy and limited thoracotomy for lung biopsy in interstitial lung disease. Ann Thorac Surg. 2000;70:1647-50.

7. Qureshi RA, Ahmed TA, Grayson AD, Soorae AS, Drakeley MJ, Page RD. Does lung biopsy help patients with interstitial lung disease? Eur J Cardiothorac Surg. 2002;21:621-6.

8. Blackhall V, Asif M, Renieri A, Civitelli S, Kirk A, Jilaihawi A, et al. The role of surgical lung biopsy in the management of interstitial lung disease: experience from a single institution in the UK. Interact Cardiovasc Thorac Surg. 2013;17: 253-7.

9. Blanco M, Obeso GA, Duran JC, Rivo JE, Garcia-Fontan E, Pena E, et al. Surgical lung biopsy for diffuse lung disease. Our experience in the last 15 years. Rev Port Pneumol. 2013;19:59-64.

10. Fibla JJ, Brunelli A, Cassivi SD, Deschamps C. Aggregate risk score for predicting mortality after surgical biopsy for interstitial lung disease. Interact Cardiovasc Thorac Surg. 2012;15:276-9.

11. Fibla JJ, Molins L, Blanco A, Royo I, Martinez Vallina P, Martinez N, et al. Video-assisted thoracoscopic lung biopsy in the diagnosis of interstitial lung disease: a prospective, multi-center study in 224 patients. Arch Bronconeumol. $2012 ; 48: 81-5$. 
12. Kayatta MO, Ahmed S, Hammel JA, Fernandez F, Pickens A, Miller D, et al. Surgical biopsy of suspected interstitial lung disease is superior to radiographic diagnosis. Ann Thorac Surg. 2013;96:399-401.

13. Kreider ME, Hansen-Flaschen J, Ahmad NN, Rossman MD, Kaiser LR, Kucharczuk JC, et al. Complications of video-assisted thoracoscopic lung biopsy in patients with interstitial lung disease. Ann Thorac Surg. 2007:83:1140-4.

14. Ooi A, Iyenger S, Ferguson J, Ritchie AJ. VATS lung biopsy in suspected, diffuse interstitial lung disease provides diagnosis, and alters management strategies. Heart Lung Circ. 2005;14:90-2.

15. Sigurdsson MI, Isaksson HJ, Gudmundsson G, Gudbjartsson T. Diagnostic surgical lung biopsies for suspected interstitial lung diseases: a retrospective study. Ann Thorac Surg. 2009;88:227-32.

16. Bando M, Ohno S, Hosono T, Yanase K, Sato Y, Sohara Y, et al. Risk of acute exacerbation after video-assisted thoracoscopic lung biopsy for interstitial lung disease. J Bronchology Interv Pulmonol. 2009;16:229-35.

17. Guerra M, Miranda JA, Leal F, Vouga L. Interstitial lung disease: diagnostic accuracy and safety of surgical lung biopsy. Rev Port Pneumol. 2009;15:433-42.

18. Morris D, Zamvar V. The efficacy of video-assisted thoracoscopic surgery lung biopsies in patients with interstitial lung disease: a retrospective study of 66 patients. J Cardiothorac Surg. 2014;9:45.

19. Pompeo E, Rogliani P, Cristino B, Schillaci O, Novelli G, Saltini C. Awake thoracoscopic biopsy of interstitial lung disease. Ann Thorac Surg. 2013;95:445-52.

20. Sonobe M, Handa T, Tanizawa K, Sato M, Sato T, Chen F, et al. Videothoracoscopy-assisted surgical lung biopsy for interstitial lung diseases. Gen Thorac Cardiovasc Surg. 2014;62:376-82.

21. Blewett CJ, Bennett WF, Miller JD, Urschel JD. Open lung biopsy as an outpatient procedure. Ann Thorac Surg. 2001;71:1113-5.

22. Lettieri CJ, Veerappan GR, Helman DL, Mulligan CR, Shorr AF. Outcomes and safety of surgical lung biopsy for interstitial lung disease. Chest. 2005;127:1600-5.

23. Luo Q, Han Q, Chen X, Xie J, Wu L, Chen R. The diagnosis efficacy and safety of video-assisted thoracoscopy surgery (VATS) in undefined interstitial lung diseases: a retrospective study. J Thorac Dis. 2013;5:283-8.
24. Yamaguchi M, Yoshino I, Suemitsu R, Osoegawa A, Kameyama T, Tagawa T, et al. Elective video-assisted thoracoscopic lung biopsy for interstitial lung disease. Asian Cardiovasc Thorac Ann. 2004;12:65-8.

25. Coutinho GF, Pancas R, Magalhaes E, Bernardo JE, Eugenio L, Antunes MJ. Diagnostic value of surgical lung biopsy: comparison with clinical and radiolog ical diagnosis. Eur J Cardiothorac Surg. 2008:33:781-5.

26. Ayed AK. Video-assisted thoracoscopic lung biopsy in the diagnosis of diffuse interstitial lung disease. A prospective study. J Cardiovasc Surg (Torino). 2003;44:115-8.

27. Ishie RT, Cardoso JJ, Silveira RJ, Stocco L. Video-assisted thoracoscopy for the diagnosis of diffuse parenchymal lung disease. J Bras Pneumol. 2009;35:234-41.

28. Nguyen W, Meyer KC. Surgical lung biopsy for the diagnosis of interstitial lung disease: a review of the literature and recommendations for optimizing safety and efficacy. Sarcoidosis Vasc Diffuse Lung Dis. 2013;30:3-16.

29. Riley DJ, Costanzo EJ. Surgical biopsy: its appropriateness in diagnosing interstitial lung disease. Curr Opin Pulm Med. 2006;12:331-6.

30. Lee YC, Wu CT, Hsu HH, Huang PM, Chang YL. Surgical lung biopsy for diffuse pulmonary disease: experience of 196 patients. J Thorac Cardiovasc Surg. 2005;129:984-90.

31. Lim SY, Suh GY, Choi JC, Koh WJ, Lim SY, Han J, et al. Usefulness of open lung biopsy in mechanically ventilated patients with undiagnosed diffuse pulmonary infiltrates: influence of comorbidities and organ dysfunction. Crit Care. 2007;11: R93.

32. Tiitto L, Heiskanen U, Bloigu R, Paakko P, Kinnula V, Kaarteenaho-Wiik R Thoracoscopic lung biopsy is a safe procedure in diagnosing usual interstitial pneumonia. Chest. 2005;128:2375-80.

33. Utz JP, Ryu JH, Douglas WW, Hartman TE, Tazelaar HD, Myers JL, et al. High short-term mortality following lung biopsy for usual interstitial pneumonia. Eur Respir J. 2001;17:175-9.

34. Sato T, Teramukai S, Kondo H, Watanabe A, Ebina M, Kishi K, et al. Impact and predictors of acute exacerbation of interstitial lung diseases after pulmonary resection for lung cancer. J Thorac Cardiovasc Surg. 2014;147:1604-11.e3.

\section{Readers who found these articles interesting may also like to read the following papers found in recent and future issues of our sister publications, Seminars in Thoracic and Cardiovascular Surgery and Operative Techniques in Thoracic and Cardiovascular Surgery!}

Current Readings: David Zeltsman. Redefining Minimally Invasive Uniportal Video-Assisted Thoracic Surgery. Semin Thorac Cardiovasc Surg. Autumn 2014;26(3):249-254.

Current Readings: Sumeet Mittal. Failed Hiatus Hernia Repair. Semin Thorac Cardiovasc Surg. Expected publication April 2015.

State of the Art: Frank Detterbeck. The ITMIG Thymic Initiative: A State of the Art for the Study of Thymic Malignancies. Semin Thorac Cardiovasc Surg. Expected publication April 2015.

State of the Art: Richard Freeman. The Theory, Practice and Future of Process Improvement in General Thoracic Surgery. Semin Thorac Cardiovasc Surg. Expected publication April 2015.

State of the Art: Eric Grogan. Using Clinical Risk Models for Lung Nodule Classification. Semin Thorac Cardiovasc Surg. Expected Publication August 2015.

Original Submission: Thomas Watson. Eliminating a need for esophagectomy: endoscopic treatment of Barrett's Esophagus with early esophageal neoplasia. Expected publication April 2015.

Editorial Commentary: Anthony Kim. Endoscopically closing doors. Semin Thorac Cardiovasc Surg. Expected publication April 2015.

Original Submission: Daniela Molena. Incidence and risk factors for respiratory complications in patients undergoing esophagectomy for malignancy: a NSQIP analysis. Semin Thorac Cardiovasc Surg. Expected publication April 2015.

Editorial Commentary: R. Taylor Ripley. Esophageal complications: What are the real results? Semin Thorac Cardiovasc Surg. Expected publication April 2015. 


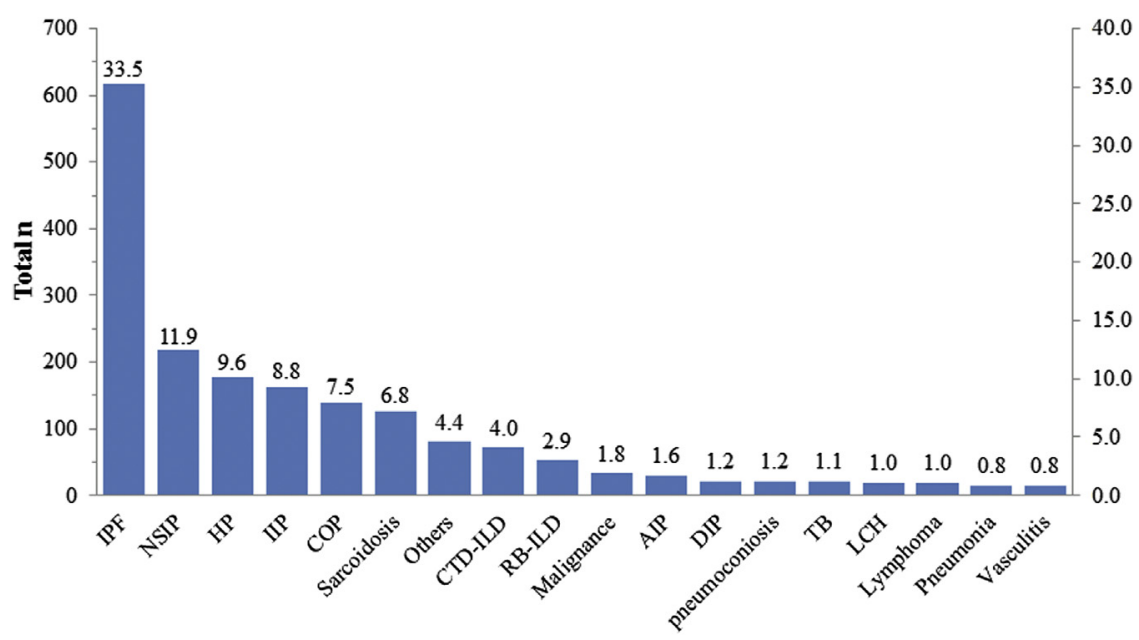

FIGURE E1. Distribution of specific diagnoses after SLB in included studies. The left y-axis represents the total number of cases, and right y-axis represents the proportion of each diagnosis. AIP, Acute interstitial pneumonia; COP, cryptogenic organizing pneumonia; $C T D-I L D$, connective tissue diseaserelated interstitial lung disease; $D I P$, desquamative interstitial pneumonitis; $H P$, hypersensitivity pneumonitis; $I I P$, idiopathic interstitial pneumonia; $I P F$, idiopathic pulmonary fibrosis; $L C H$, Langerhans cell histiocytosis; NSIP, nonspecific interstitial pneumonia; $R B-I L D$, respiratory bronchiolitis associated interstitial lung disease; $T B$, tuberculosis. 